\title{
Inverse associations between cycling to work, public transport, and overweight and obesity: Findings from a population based study in Australia
}

\author{
Li Ming Wen *, Chris Rissel \\ Health Promotion Service, Sydney South West Area Health Service, Level 9, King George V Building, \\ Missenden Road, Camperdown, NSW 2050, Australia
}

Available online 23 August 2007

\begin{abstract}
Objective. The aim of this study was to investigate the associations between various modes of transport to work and overweight and obesity, in men and women.

Methods. The study was conducted using data from a representative sample of 6810 respondents who reported being in the workforce, extracted from the 2003 New South Wales Adult Health Survey, Australia. Logistic regression modeling adjusted for potential confounders.

Results. Men who cycled to work were significantly less likely to be overweight and obese (39.8\%) compared with those driving to work (60.8\%), with an adjusted odds ratio of 0.49 (95\% CI: $0.31-0.76)$ and much less likely to be obese (5.4\%) with an adjusted odds ratio 0.34 (95\% CI: $0.13-0.87$ ). Men who used public transport to work were also significantly less likely to be overweight and obese (44.6\%) with an adjusted odds ratio of 0.65 ( $95 \%$ CI: $0.53-0.81)$. However, these inverse relationships were not found in women.

Conclusions. These findings support recommendations to cycle to work or use public transport as a strategy to maintain healthy weight for men. Although healthy weight cannot be causally attributed to cycling and use of public transport in this study, the link is plausible, and increased cycling and use of public transport would have positive benefits for the environment and health in any case.
\end{abstract}

Crown Copyright (C) 2007 Published by Elsevier Inc. All rights reserved.

Keywords: Active transport; Cycling; Overweight and obesity; Population survey

\section{Introduction}

Our increasing reliance on private motor vehicles has not only led to traffic congestion and air pollution, and makes a significant contribution to green house gas emission but also contributes to lower levels of physical activity in the general population (WHO, 1999). The World Health Organisation has identified motor vehicles as a major contributor to sedentary lifestyles and therefore a potential link between using motor vehicles and overweight and obesity.

Active transport is any form of transport that involves physical activity, such as walking, cycling, and travelling by public transport (Davis, 1999). It has been widely promoted as a way of improving the environment, increasing physically active

* Corresponding author. Fax: +61 295159056.

E-mail address: 1mwen@email.cs.nsw.gov.au (L. Ming Wen). lifestyles and preventing overweight and obesity. The rationale for this health promotion strategy has been noted by various studies which found associations between driving, level of physical inactivity and overweight and obesity (Frank et al., 2004; Gorden-Larsen et al., 2005; Wen et al., 2006).

In a previous analysis (Wen et al., 2006), we found that driving to work was significantly associated with being overweight and obese. However, this association needs to be further explored by examining each of the various modes of transport and their unique associations with overweight and obesity and whether these associations persist across gender.

\section{Methods}

We extracted a subset of data from the 2003 New South Wales Adult Health Survey, which was conducted by telephone among a representative sample of residents aged 16 years or over in NSW, Australia (NSW Department of Health, 2004). The data set comprised a representative sample of 6810 respondents who 
reported being in the workforce, with an overall response rate of $67.9 \%$. These respondents were asked about their modes of transport to work, which were determined by responses to the question, "How do you usually get to work?" and allowed for multiple responses. The responses included travel by public transport (train, bus, ferry, tram), bicycle or walking only, or travel by car as the driver or passenger or working from home.

Prevalence estimates of study variables were weighted for the probability of selection based on the household size, and for age and sex based on NSW component of the 2001 Australian Census of Population and Housing. Weighted data were used for all statistical analyses.

The measures of interest included self-reported height and weight, level of physical activity, gender, age group, marital status, level of education, and language spoken at home. A detailed description of the measures and analyses is reported elsewhere (NSW Department of Health, 2007; Wen et al., 2006).

Body Mass Index (BMI) was derived from self-reported height and weight, which was calculated by dividing the weight (in kilograms) by the height (in meters) squared. BMI was then classified into four categories: underweight $(<18.5)$, normal weight (18.5-24.9), overweight (25-29.9), and obese $(\geq 30)$.

An adequate level of physical activity was defined as undertaking physical activity for a total of $150 \mathrm{~min}$ per week over five separate occasions (NSW Department of Health, 2004). The total minutes were calculated by adding minutes in the last week spent walking (continuously for at least $10 \mathrm{~min}$ ), minutes doing moderate physical activity, plus minutes doing vigorous physical activity multiplied by two.

Relationships between study and outcome variables were examined using Pearson Chi-square tests and Mantel-Haenszel trend tests. Variables that were found to be associated with overweight and obesity, or obesity in bivariate analyses were entered into a logistic regression model.

In the logistic regression analysis, all variables were entered in one step and removed from the model according to their statistical significance on entry, and whether they met the removal criteria $(p=0.10)$ (which is the algorithm used by SPSS for Windows 14.0 using the "enter" modeling option in the logistic regression procedure). The tests for confounding and interaction and tests of goodness of fit of the model were conducted. No significant interactions were detected between the variables of interest. Each variable was adjusted for all other variables in the model as presented in the table. Adjusted odds ratios (AORs) with $95 \%$ confidence intervals were then calculated as a measure of strength of association. Logistic regression models were stratified by sex.

\section{Results}

Distribution of modes of transport to work, level of physical activity weight status, and other demographics of the study population included in the analyses are shown in Table 1. Seventy-two percent of men drove to work compared with $68 \%$ of women. More men cycled to work than women $(2.7 \%$ vs. $0.4 \%$ ). Men were significantly more likely to be overweight compared with women ( $42 \%$ vs. $23 \%)$; however, the proportion of obese men was similar to that of women.

Table 2 shows the association between modes of transport and overweight and obesity stratified by gender. It presents the final logistic regression model estimating the odds of being overweight and obesity or being obese after adjusting for the other variables in the tables. Men who cycled to work were significantly less likely to be overweight and obese (39.8\%) compared with those driving to work $(60.8 \%)$, with an adjusted odds ratio of $0.49(95 \%$ CI: 0.31-0.76). Furthermore, male cyclists were much less likely to be obese (5.4\%) compared to drivers (15.5\%), with an adjusted odds ratio 0.34 (95\% CI: $0.13-0.87)$. In addition, men who used public transport to get to work
Table 1

Distribution of modes of transport to work, level of physical activity weight status, and other demographics of the study population by gender, using data collected from the 2003 New South Wales Adult Health Survey, Australia

\begin{tabular}{|c|c|c|c|}
\hline \multirow[t]{2}{*}{ Characteristics } & \multirow{2}{*}{$\begin{array}{l}\frac{\text { Men }(n=3810)}{N(\text { column \%) }} \\
\text { (weighted) }\end{array}$} & \multirow{2}{*}{$\begin{array}{l}\frac{\text { Women }(n=3022)}{N(\text { column } \%)} \\
\text { (weighted) }\end{array}$} & \multirow{2}{*}{$\begin{array}{l}\text { Total }(n=6810 \\
N \text { (column \%) } \\
\text { (weighted) }\end{array}$} \\
\hline & & & \\
\hline \multicolumn{4}{|c|}{ Modes of transport to work } \\
\hline Driving & $2507(72.1)$ & $1809(68.4)$ & $4397(70.5)$ \\
\hline Public transport & $505(14.5)$ & $455(16.5)$ & $960(15.4)$ \\
\hline Walking & $195(5.6)$ & $216(7.8)$ & $411(6.6)$ \\
\hline Bike & $93(2.7)$ & $10(10.4)$ & $103(1.7)$ \\
\hline Work at home & $176(5.1)$ & $\begin{array}{l}193(7.0) \\
p<0.01\end{array}$ & $369(5.9)$ \\
\hline
\end{tabular}

Level of physical activity

$\begin{array}{llll}\text { Adequate } & 1905(50.0) & 1331(44.1) & 3236(47.4) \\ \text { Inadequate } & 1906(50.0) & 1690(55.9) & 3596(52.6) \\ & & p<0.01\end{array}$

Weight status

Under weight

Normal

Overweight

$33(0.9)-138(4.8)$

$171(2.6)$

Obese

$1559(41.7) \quad 1664(57.8)$

$1573(42.0) \quad 667(23.2)$

$3223(48.7)$

$2240(33.8)$

$409(14.2)$

986 (14.9)

$p<0.01$

Age group
$16-30$
$31-40$
$41-50$
$51-60$
$60+$

$\begin{array}{cl}1136(29.8) & 925(30.6) \\ 947(24.9) & 707(23.4) \\ 891(23.4) & 792(26.2) \\ 626(16.4) & 463(15.3) \\ 210(5.5) & 135(4.5) \\ & p<0.05\end{array}$

$2061(30.2)$

$1654(24.2)$

$1683(24.6)$

$1089(15.9)$

$345(5.0)$

Marital status

Married

Widowed

$\begin{array}{cl}2200(57.8) & 1682(55.8) \\ 22(0.6) & 64(2.1) \\ 271(7.1) & 310(10.3) \\ 1313(34.5) & 956(31.7) \\ & p<0.01\end{array}$

$3882(56.9)$

$86(1.3)$

$581(8.5)$

Separated/divorced

Never married

$p<0.01$

$2271(33.3)$
Level of education
Primary and some high school
Competed high school/
$624(16.9) \quad 583(20.4)$
$\mathrm{TAFE}^{\mathrm{a}} /$ diploma
University/other tertiary $1081(29.3) \quad 976(34.1)$ degree
$p<0.05$

1207 (18.4)

$3290(50.2)$

2057 (31.4)

Main language spoken at home

$\begin{array}{lrlr}\text { English } & 3211(85.3) & 2593(87.2) & 5804(86.2) \\ \text { Other } & 552(14.7) & 379(12.8) & 931(13.8) \\ & & p<0.05\end{array}$

${ }^{a}$ TAFE refers to Technical and Further Education.

were also significantly less likely to be overweight and obese $(44.6 \%)$ with an adjusted odds ratio of 0.65 (95\% CI: 0.53-0.81). However, the use of public transport did not appear to be associated with lower levels of obesity in men.

It was noted that these relationships between cycling and use of public transport to work and lower levels of overweight and obesity were not found in women. Somewhat surprisingly, walking to work was not found to be inversely 
Table 2

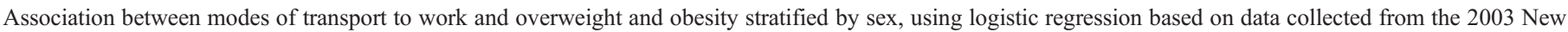
South Wales Adult Health Survey, Australia

\begin{tabular}{|c|c|c|c|c|c|c|c|c|}
\hline \multirow[t]{3}{*}{ Factors } & \multicolumn{4}{|l|}{ Men } & \multicolumn{4}{|c|}{ Women } \\
\hline & \multicolumn{2}{|c|}{ Overweight and obese } & \multicolumn{2}{|c|}{ Obese } & \multicolumn{2}{|c|}{$\underline{\text { Overweight and obese }}$} & \multicolumn{2}{|c|}{ Obese } \\
\hline & $\%$ & $\operatorname{AOR}^{a}\left(95 \% \mathrm{CI}^{\mathrm{b}}\right)$ & $\%$ & AOR $(95 \% \mathrm{CI})$ & $\%$ & $\operatorname{AOR}(95 \% \mathrm{CI})$ & $\%$ & AOR $(95 \% \mathrm{CI})$ \\
\hline \multicolumn{9}{|l|}{ Modes of transport to work } \\
\hline Driving & 60.8 & 1 & 15.5 & 1 & 38.8 & 1 & 14.0 & 1 \\
\hline Public transport & 44.6 & $0.65(0.53-0.81)$ & 11.1 & $0.84(0.61-1.15)$ & 30.0 & $0.86(0.67-1.10)$ & 10.8 & $0.87(0.61-1.24)$ \\
\hline Walking & 52.7 & $0.91(0.65-1.25)$ & 17.4 & $1.32(0.87-1.99)$ & 38.9 & $1.26(0.92-1.77)$ & 15.7 & $1.48(0.98-2.24)$ \\
\hline Bike & 39.8 & $0.49(0.31-0.76)$ & 5.4 & $0.34(0.13-0.87)$ & 30.3 & $1.16(0.27-4.94)$ & 0 & - \\
\hline Work at home & 61.3 & $0.80(0.57-1.41)$ & 18.2 & $1.09(0.71-1.68)$ & 42.3 & $1.07(0.77-1.47)$ & 13.5 & $0.84(0.53-1.34)$ \\
\hline \multicolumn{9}{|l|}{ Level of physical activity } \\
\hline Adequate & 52.9 & 1 & 11.8 & 1 & 30.3 & 1 & 9.4 & 1 \\
\hline Inadequate & 62.0 & $1.22(1.05-1.41)$ & 18.5 & $1.63(1.34-2.00)$ & 43.3 & $1.52(1.28-1.81)$ & 16.8 & $1.88(1.46-2.42)$ \\
\hline \multicolumn{9}{|l|}{ Age group } \\
\hline $16-30$ & 39.0 & 1 & 9.0 & 1 & 26.1 & 1 & 9.2 & 1 \\
\hline $31-40$ & 62.1 & $1.94(1.56-2.41)$ & 14.7 & $1.45(1.05-2.01)$ & 34.1 & $1.03(0.78-1.35)$ & 11.6 & $0.96(0.65-1.42)$ \\
\hline $41-50$ & 66.7 & $2.01(1.58-2.56)$ & 17.5 & $1.79(1.26-2.52)$ & 43.0 & $1.33(1.01-1.76)$ & 15.8 & $1.18(0.79-1.76)$ \\
\hline $51-60$ & 67.0 & $2.04(1.57-2.66)$ & 21.1 & $2.21(1.54-3.71)$ & 51.2 & $1.85(1.35-2.55)$ & 19.9 & $1.65(1.07-2.55)$ \\
\hline $60+$ & 67.1 & $1.83(1.22-2.75)$ & 22.4 & $1.52(0.88-2.61)$ & 51.2 & $1.45(0.83-2.45)$ & 18.5 & $1.41(0.72-2.78)$ \\
\hline \multicolumn{9}{|l|}{ Marital status } \\
\hline Married & 65.9 & 1 & 17.0 & 1 & 42.8 & 1 & 15.3 & 1 \\
\hline Widowed & 77.3 & $5.03(0.82-31.00)$ & 36.4 & $3.39(1.22-9.41)$ & 44.3 & $0.95(0.48-1.89)$ & 17.2 & $1.21(0.54-2.72)$ \\
\hline Separated/divorced & 65.6 & $0.93(0.69-1.25)$ & 20.7 & $1.27(0.89-1.79)$ & 44.3 & $1.00(0.76-1.32)$ & 17.1 & $0.99(0.69-1.43)$ \\
\hline Never married & 41.2 & $0.54(0.44-0.65)$ & 10.7 & $0.96(0.72-1.28)$ & 25.3 & $0.64(0.52-0.85)$ & 9.1 & $0.79(0.55-1.15)$ \\
\hline \multicolumn{9}{|l|}{ Level of education } \\
\hline Primary and some high school & 62.5 & 1 & 20.9 & 1 & 48.6 & 1 & 18.0 & 1 \\
\hline Competed high school/diploma & 58.7 & $0.96(0.73-1.19)$ & 15.3 & $0.76(0.59-0.98)$ & 37.9 & $0.77(0.62-0.97)$ & 14.4 & $0.82(0.61-1.10)$ \\
\hline University/other tertiary degree & 51.8 & $0.69(0.55-0.87)$ & 11.8 & $0.51(0.38-0.69)$ & 29.1 & $0.50(0.39-0.64)$ & 8.2 & $0.45(0.32-0.63)$ \\
\hline \multicolumn{9}{|l|}{ Main language spoken at home } \\
\hline English & 59.0 & 1 & 15.3 & 1 & 37.9 & 1 & 14.0 & 1 \\
\hline Other & 51.6 & $0.63(0.52-0.79)$ & 15.2 & $1.05(0.79-1.39)$ & 36.1 & $0.95(0.73-1.23)$ & 13.6 & $0.81(0.55-1.19)$ \\
\hline
\end{tabular}

${ }^{a}$ AOR (adjusted odds ratio) was obtained after each variable was adjusted for all other variables in the table.

b CI: confidence interval.

associated with overweight and obesity, or obesity, in either men or women.

As expected, other variables including age, education level, language spoken at home, and level of physical activity were also found to be associated with being overweight and obese in men and women.

\section{Discussions}

The findings of this study indicate that those people physically active in their journey to work were the least likely to be overweight or obese after taking into account leisure-time physical activity. Cycling, in particular, had a strong inverse association with being obese. However, the healthy weight benefits of cycling and use of public transport were only found in men. Due to a small number of women who cycled, the association between transport mode and weight in women could not be analysed in this study.

The gender difference in the relationships between modes of transport to work and overweight and obesity found in this study is interesting and warrants further investigation. We are not aware of other studies with a similar finding. The very low proportion of women cycling to work may have contributed to the lack of association with weight. However, it is unclear why using public transport to work should be associated with healthy weight for men, but not women.

Walking has been widely promoted for increasing physical activity and decreasing obesity (Oja et al., 1998). Walking to work could be an opportunity for physical activity for some people, with many positive health and environment outcomes. However, the absence of an association between walking to work and overweight and obesity suggests that this form of walking may not be sufficiently vigorous, or of sufficient distance or duration to have a detectable benefit on weight.

Compared with walking, the healthy benefits of cycling are somewhat greater because the intensity of effort is greater (Oja et al., 1998). The Copenhagen Heart Study found that people who did not cycle to work experienced a $39 \%$ of 
higher mortality rate than those who did (Andersen et al., 2000). It was not surprising that cycling to work showed a strong inverse association with being obese in this analysis. Public policy in the health, transport, and recreation sectors should be enhanced to promote greater levels of cycling (Rissel, 2003).

\section{Strengths and limitations}

This study explores in some detail the relationships between various means of transport and overweight and obesity with a particular focus on gender differences. The strengths of this study include the use of the data set extracted from a statewide population-based survey with a relatively large sample size. It also demonstrates the value of gender stratification in investigating the relationships between modes of transport used and overweight and obesity. We acknowledge the need to exercise caution in making conclusions about causality based on cross-sectional surveys of this kind. Further longitudinal studies are required. In addition, the findings are also limited by the measures of modes of transport to work which did not take into account time spent and distance traveled as well as why some people chose active transport. The choice issue is important because relatively few people cycle to work and those who do may have specific individual characteristics. There is a risk of selection bias in this study due to non-responses and missing values. Finally, potential measurement bias could not be avoided due to the nature of a self-reported health survey of this kind.

\section{Acknowledgment}

The data used in this study were collected by the Centre for Epidemiology and Research, NSW Department of Health, Australia.

\section{References}

Andersen, L., et al., 2000. All-cause mortality associated with physical activity during leisure time, work, sports and cycling to work. Arch. Intern. Med. $160,1621-1628$.

Davis, A., 1999. Active Transport: A Guide to the Development of Local Initiatives to Promote Walking and Cycling, Health Education Authority, London.

Frank, L.D., Andresen, M.A., Schmid, T.L., 2004. Obesity relationships with community design, physical activity, and time spent in cars. Am. J. Prev. Med. 27 (2), 87-96.

Larsen, P., Nelson, M.C., Beam, K., 2005. Associations among active transportation, physical activity, and weight status in young adults. Obes. Res. 13 (5), 868-875.

NSW Department of Health. http://www.health.nsw.gov.au/public-health/ phbsup/ahs2007.pdf accessed on May 4, 2007.

NSW Department of Health, Centre for Epidemiology and Research, 2004. New South Wales Adult Health Survey 2003. NSW Public Health Bull, 15 (S-4).

Oja, P., Vuori, I., Paronen, O., 1998. Daily walking and cycling to work: their utility as health-enhancing physical activity. Patient Educ. Couns. 33, S87-S94.

Rissel, C., 2003. Ride your bike: healthy policy for Australians. Health Promot. J. Australia 14 (3), 151-153.

Wen, L.M., Orr, N., Millett, C., Rissel, C., 2006. Driving to work and overweight and obesity: findings from the 2003 New South Wales Health Survey, Australia. Int. J. Obes. 30, 782-786.

WHO Regional Office for Europe, 1999. Charter on Transport, Environment and Health, Third Ministerial Conference on Environment and Health, London. 